last week) is present in the urine during a course of years without other renal symptoms. The term "albuminorrhoea" has been proposed to denote these cases. They are, I believe, notwithstanding the statements recently made, not common, and their comparative rarity has hindered the growth of accurate knowledge concerning them. When the cases belonging to other classes have been sifted out it will be found that few observers are familiar with more than one or two of the class alluded to, and hence their impressions are necessarily derived from too small a field of observation. Here the record and careful analysis of a number of cases could hardly fail to lead to conclusions of value. In such cases we need above all the guidance of necropsies, and these are very seldom obtained. It has appeared to me not improbable that mechanical conditions, sometimes congenital, affecting one kidney or part of one kidney, may account for some of these cases. Mr. Henry Lee ${ }^{1}$ once made a very suggestive postmortem examination of the body of a man who had long had albuminuria without apparent cause. $\mathrm{He}$ found intussusception of one ureter. Another class of cases has been well described by Dr. Clement Dukes-temporary albuminuria, with headache, syncope and high vascular tension occurring in the period of youth-but these I think are on the border line of the present inquiry. There would seem to be inflammatory hyperæmia of the kidney in such cases. A further considerable class of cases which is of much importance to the life assurance examiner is that of temporary albuminuria from accidental causes, such as shock to the surface in bathing, severe muscular exercise, or ingestion of albuminous food-typical "physiological albuminuria," to use the phrase of Sir W. Roberts. Yet another class might be addedspurious albuminuria, in which the albomen is derived from other parts of the urinary system than the kidney; catarrh of the renal pelvis or ureter, or of the bladder, produces such a result. Slight gleet in young men vitiates our tests in not a few life assurance cases ; and, lastly, as linted by Dr. Routh, leucorrhœa is, in women, an exceedingly common cause of spurious albuminuria. Dr. Maguire and others have laid much stress upon the connexion between albuminuria and conditions of vascular tension and have advanced the view that, in most of the classes alluded to, the causes operated by means of alterations of the blood tension. There can be no doubt that the tension of the vessels is a factor of great moment in many of these cases and that there is a true "albuminuria of Iow tension" as well as "albuminuria of high tension." But added experience has convinced me that there are other factors at work in many cases and that vascular tension will not explain nearly all the instances met with.

One word with regard to statistics of albuminuria. Dr. Lauder Brunton is reported to have drawn, at the meeting of the Medical Society, a comparison between the proportion of albuminuria cases found amongst healthy men by himself in England ( 2 per cent.) and by observers in America ( 9 per cent.) respectively, and to have inferred from these statistics the greater prevalence of albuminuria in the latter country. But are not such statistics absolutely useless for comparison, since they depend entirely on the methods of the observer? I have myself stated elsewhere ${ }^{2}$ the results of the examination of 282 presumably healthy adults for life assurance, amongst whom I found eighty-six, or 30 per cent., to show traces of albumen in their urine. No two observers will exactly coincide in their appreciation of a "trace" of albumen--that which one disregards, another, with finer methods, will enter as albuminoids. What then should be the scope of the inquiry which you, Sirs, have proposed? I take its subject to be "albuminuria unattended by other evidence of kidney disease." Records of cases, especially such as cover a series of years, should be collected. To what sources can we look for such records? I think with Dr. Tyson that it would be very difficult to make much use of the records of insurance offices. Their medical reports are commonly too brief for this purpose, and to be of use the observations almost need to be made with this special end in view. It is from the casebooks of medical men, themselves interested in this subject, that material must be obtained-the notes of the cases of persons in the middle and upper ranks of society, who have been watched for years by their physicians. The records of necropsies should especially be coveted. What should be our aims in collecting and analysing these records ? To place the

The Lancer. March 8 th, 1890.

2 Albuminuria in relation to Life Assurance: a Paper Introductory to a Special Discussion. Transactions of the Hunterian Sodiet d891-92. See also THE LANCET, Dec. 12th, 1891. cases in clinical groups so far as these can be defined. To do this one has to take account of all associated or pre-existing conditions, especially of vascular tension and blood conditions, and of inherited or associated diathesis. It would not be difficult to sketch out a schedule for the description of these cases. Cyclic albuminuria is so common that a few well chosen cases should suffice to represent this class, those in particular which extend over a good many years. Cases of permanent albuminuria without apparent cause should be stated in more fulness.

Lastly, there are two features in the records which would require especial attention. One is the kind of albumen present-whether globulin, propeptone or any other modification formed a part or the whole of it; where possible the tests employed should be stated. The other feature is the after-history - whether progressive renal disorder eventually supervened. Conducted on some such lines as these, I cannot but think that the inquiry would prove of much service, and that it might supply us with solid groundwork for the prognosis of these difficult cases.

I am, Sirs, yours truly,

Finsbury-square, Narch 11th, 1893, R. Hingston Fox.

\section{THE TREATMENT OF HAMORRHOTDS AND PROLAPSE OF THE RECTUM BY CLAMP AND CAUTERY.}

To the Editors of THE LANCET.

SIRS,-Mr. Henry Smith's article, published in THE LANCET of March 4th, on the above subject, might lead one to imagine that the operation by the clamp and cautery possessed every possible advantage. With all due deference to such an authority, I think it only right to recall to the minds of the readers of THE LANCET the disadvantages of this mode of treatment. It is at least four times as fatal as any other method of removing hæmorrhoids. The pain is as great as, if not greater than, that proceeding from other modes, for one should be well aware that, in the rectum as in other parts of the body, a burn is one of the most painful of all injuries; similarly, contraction, another usual sequela of burning, is by no means absent after the clamp and cautery procedure. Agair. secondary hæmorrhage is likely to occur on the separation of the sloughs caused by burning. No doubt this operation may be suitable in selected instances, but to apply it to all cases of hæmorrhoids runs too near to the Procrustes' bed method of procedure to deserve much commendation at this period of surgery. It has been my lot to operate upon cases of hæmorrhoids in which the clamp and cautery had been used several years before. I treated them by crushing or by ligature, and was assured by the patients that the pain and after-trouble were far less than they had suffered after the burning operation. Tetanus, pyæmia, secondary hæmorrhage and so forth are almost unknown now, and in his reference to them Mr. Smith must be thinking of the era when the clamp and cautery were extensively used.

I am, Sirs, yours truly, HERBERT Allingham, F.R.C.S. Eng.

Grosvenor-square, W., March 22nd, 1883.

\section{"DENTAL ADVERTISING." To the Eaitors of THE LANCET.}

SIRs, - Your correspondent "A Looker On" thinks the agitation against dental advertising injudicious because it cannot possibly bear fruit. I hope it will bear good fruit. It is already awakening a great many to the disgrace of it and the degrading influence it has upon the whole dental profession, I trust this feeling will penetrate into the medical profession generally and through it into the public mind, and a man who makes a trade of an honourable profession-who seeks to emulate the proprietors of a soap or a mustard-will be scouted by all. It is true the General Medical Council admitted many advertisers to the Dentists' Register, but by so doing the General Medical Council did not make itself a party to advertising or sanction any vested interest in it, as your correspondent suggests. On the contrary, the General Medical Council have now a power over them they did not before possess. The Master of the Rolls and Lord Justices Lopes and Fry, sitting as a court of appeal in the Partridge v. General Medical Council case, held that advertising was disgraceful conduct in a professional respect, and "if there were evidence of it the decision of the Council is final and 